\title{
A Novel Model for Cloud Based Mobile Learning System
}

\author{
Areej Omar Baalghusun, M. Rizwan Jameel Qureshi \\ Department of Information Technology, Faculty of Computing and Information Technology, King Abdulaziz \\ University, Jeddah, Saudi Arabia \\ Email: areejomar_2008@yahoo.com,rmuhammd@kau.edu.sa
}

\begin{abstract}
Mobile learning (M-learning) becomes revolutionary way to educate the world with the mass advancement in information and communications technology (ICT). It is difficult to deal with m-learning due to increasing number of users, services, education contents and resources and modes to deploy. Cloud computing, with its dynamic scalability and virtualized resources usage, is widely deployed for several applications in many organizations. It has a significant impact in the educational and learning environment. This paper presents a new model for mobile learning system in cloud computing environment that is enriched with high performance computing (HPC) and graphical processing unit (GPU) cluster infrastructure. This model aggregates the power with new technologies to implement M-leaning process more effective with high performance and quick response.
\end{abstract}

Index Terms-Distance Electronic Learning, M-Learning, Mobile Cloud Computing, High Performance Computing, Graphical Processing Unit.

\section{INTRODUCTION}

Educational institutions are rapidly adapting new methods of learning instead of using the traditional ones. Education is entered into a new era due to the digital revolution and advancement in information and communications technology (ICT). The traditional class room teaching is enriched with electronic learning (Elearning) and mobile learning (M-learning) enabling the learning journey more effective and enjoyable [1].

One of the forms of e-learning is distance e-learning (DeL). It is a combination of distance education and elearning that is characterized by the extensive use of information and communications technology (ICT). It delivers education and instruction with the use of synchronous and asynchronous online communication in an interactive learning environment or virtual communities, in lieu of a physical classroom, to bridge the gap in temporal or spatial constraints. DeL combines the strengths and advantages of distance education and elearning [2].

Mobile technology is now used as supplement to Del and it is also adapted in educational fields as M-learning. M-learning provides a flexible learning environment to its users regardless of geographical location/time zone [4].
The main advantages of M-learning are improved interaction, portability, collaborative, engaging learners, increases motivation, just-in-time learning and autonomy [5]. The main limitations of m-learning are Internet availability, battery life, bandwidth, number of file formats supported by a specific device, content security or copyright issue from authoring group, multiple standards, multiple screen sizes, multiple operating systems, reworking existing e-learning materials for mobile platforms, limited memory, risk of sudden obsolescence, the small screens and limited processing power [6]. Cloud computing is introduced to overcome these limitations [3] and it currently emerges as a hot research topic due to flexible dynamic infrastructure, quality of services (QoS) and configurable software services [7]. M-learning using cloud is a new research area and it is termed as mobile cloud computing (MCC). MCC has many advantages as follows [8].

- Sharing information and applications without the need of complex and costly hardware and software because the computations are run in the cloud.

- Enhanced features and functionalities of mobile devices through new cloud applications.

- Ease of access and development.

- Cheap for cloud computing vendors to build complex mobile cloud applications.

- Improved data storage capacity and processing power.

This paper proposes a new model of mobile learning system in cloud computing, by using high performance computing (HPC) and graphical processing unit (GPU) cluster infrastructures enrich with mobile and wireless devices such as smart phones, notebook and tablets [911]. The proposed model provides high performance and fast respond (three sixty five days a year) to its users. The proposed model also supports educational institutions with diverse learning styles in different learning contexts to facilitate learning and information/knowledge sharing through cloud computing. The proposed model is suitable for intensive and fast processing (computing) to 3D modeling of graphics visualization and animation in the areas of health care, medical learning, chemistry experiments and programming courses.

The proposed model provides consistent Internet service to users and it also manages load balancing on 
HPC and GPU infrastructure in active/passive mode. Another main advantage is the ability to deal with either planned or unplanned service outage using load balancer servers to handle system traffic. It allows flexibility to perform maintenance on one server without effecting services. This is accomplished by transferring all traffic to one server and placing the load balancer in active/passive mode. Software upgrades and updates can

Table 1. The Contributions and Limitations in the Related Work

\begin{tabular}{|c|c|c|}
\hline Title of Paper & Contribution & Limitations \\
\hline $\begin{array}{l}\text { Mobile Learning via SMS at } \\
\text { Open University Malaysia: } \\
\text { Equitable, Effective, and } \\
\text { Sustainable [12]. }\end{array}$ & $\begin{array}{l}\text { A proposal of implementing mobile learning (m- } \\
\text { learning) via short message service (SMS). }\end{array}$ & $\begin{array}{l}\text { High cost, limited number of characters in a single message, use } \\
\text { of text message only and late delivery of SMS. There is no } \\
\text { evidence in support of the proposal in real time communications } \\
\text { between student and instructors. }\end{array}$ \\
\hline $\begin{array}{l}\text { The Design and Development of } \\
\text { Mobile Collaborative Learning } \\
\text { Application Using Android [13]. }\end{array}$ & \begin{tabular}{|l} 
A proposal of designing and developing \\
standalone client/server application using android \\
platform.
\end{tabular} & $\begin{array}{l}\text { Installing, updating and maintaining the application on device } \\
\text { those will consume high device storage and more cost. Other } \\
\text { problems in the proposal are that it supports only android devices } \\
\text { platform and it has low network transmission rate and limited } \\
\text { data processing (computing) power. }\end{array}$ \\
\hline \begin{tabular}{|l|} 
Context-Aware Adaptive and \\
Personalized Mobile Learning \\
Delivery Supported by UoLmP \\
[14].
\end{tabular} & $\begin{array}{l}\text { A proposal of presenting context-aware adaptive } \\
\text { and personalized mobile learning system, namely } \\
\text { the Units of Learning mobile Player (UoLmP) } \\
\text { aiming to support semi-automatic adaptation of } \\
\text { learning activities. }\end{array}$ & $\begin{array}{l}\text { Resources consuming, low battery life, android platform } \\
\text { dependency, low network transmission rate and limited data } \\
\text { processing (computing) power to analysis data. There is no real } \\
\text { time communications between students. }\end{array}$ \\
\hline $\begin{array}{|llr|}\text { Enhanced } & \text { M-Learning } & \text { with } \\
\text { cloud } \quad \text { computing: } & \text { The } \\
\text { Bangladesh case [1]. } & \\
\end{array}$ & $\begin{array}{l}\text { A proposal of m-leaning cloud computing } \\
\text { architecture. }\end{array}$ & $\begin{array}{l}\text { Limited processing power, input capability, lack of resources and } \\
\text { memory capacity, small screen and no validation. }\end{array}$ \\
\hline $\begin{array}{l}\text { Research of mobile learning } \\
\text { system based on cloud } \\
\text { computing [5]. }\end{array}$ & $\begin{array}{l}\text { A proposal of presenting cloud computing based } \\
\text { m-learning system model, the functional design } \\
\text { and architecture framework for the system. }\end{array}$ & $\begin{array}{l}\text { Limited data processing (computing) power, and no validation of } \\
\text { the proposed cloud computing based m-learning model. }\end{array}$ \\
\hline $\begin{array}{|lll|}\begin{array}{l}\text { Interactive } \\
\text { learning }\end{array} \text { system } & \begin{array}{l}\text { live } \\
\text { in }\end{array} \text { cloud } \\
\text { environment [15]. } & & \\
\end{array}$ & \begin{tabular}{|l|} 
A proposal of developing interactive mobile live \\
video learning system in cloud environment.
\end{tabular} & $\begin{array}{l}\text { installing the application in the devices which will consume the } \\
\text { storage, limited data processing (computing) power, and it is not } \\
\text { attach to educational organization or institution. }\end{array}$ \\
\hline \begin{tabular}{|l|} 
Mobile cloud computing \\
educational tool for image/video \\
processing algorithms [16].
\end{tabular} & $\begin{array}{l}\text { Presents Mobi4Ed mobile educational tool to } \\
\text { take advantage of cloud computing. The tool } \\
\text { processes complex and large computations and } \\
\text { images and videos. }\end{array}$ & $\begin{array}{l}\text { Android platform dependency, no evidence to include real time } \\
\text { video and no assessment to quantify and validate the usefulness } \\
\text { of the tool. }\end{array}$ \\
\hline $\begin{array}{l}\text { Mobile cloud framework } \\
\begin{array}{l}\text { architecture for } \\
\text { institutions [17]. }\end{array}\end{array}$ & \begin{tabular}{|l|} 
A proposal of presenting a conceptual framework \\
for educational cloud architecture design.
\end{tabular} & $\begin{array}{l}\text { Not covering the relevant aspects related to design and } \\
\text { development of a mobile cloud computing architecture. It } \\
\text { provides a generic view of the mobile cloud computing } \\
\text { architecture. }\end{array}$ \\
\hline $\begin{array}{l}\text { Application for Mobile Cloud } \\
\text { Learning [18]. }\end{array}$ & $\begin{array}{l}\text { A proposal of presenting a model for mobile } \\
\text { cloud learning system and its application. It is an } \\
\text { effort to enhance the m-learning system. }\end{array}$ & $\begin{array}{l}\text { The paper doesn't mention any details to describe the model, } \\
\text { limited data processing (computing) power, and no validation of } \\
\text { the proposed mobile cloud learning model. }\end{array}$ \\
\hline $\begin{array}{l}\text { A Cloud Based M-learning } \\
\text { Architecture for Higher } \\
\text { Education [19]. }\end{array}$ & $\begin{array}{l}\text { A proposal of presenting new architecture for } \\
\text { mobile distance learning system in an extended } \\
\text { cloud computing environment enriched with } \\
\text { mobiles and wireless devices. }\end{array}$ & $\begin{array}{l}\text { Limited data processing (computing) power and the paper } \\
\text { doesn't validate the work. The paper will work further on } \\
\text { improving the bandwidth, and implementing more effective } \\
\text { dynamic network monitoring. }\end{array}$ \\
\hline $\begin{array}{l}\text { Social media for learning: A } \\
\text { mixed methods study on high } \\
\text { school students' technology } \\
\text { affordances and perspectives } \\
{[20] .}\end{array}$ & $\begin{array}{l}\text { The study recommend that social media is a } \\
\text { helpful learning tool. }\end{array}$ & $\begin{array}{l}\text { There is neither clear indication of the research question nor } \\
\text { methodological aspects to understand the empirical evaluation of } \\
\text { research. The research design described for evaluation is survey } \\
\text { and it is not the most appropriate research method to evaluate the } \\
\text { impact of research. }\end{array}$ \\
\hline
\end{tabular}

be deployed to the passive server and tested in a production environment. It is easy to maintain servers ensuring that users do not experience any outage and satisfy.

Further paper is organized as follows. Section 2 summarizes the related work to formulate the problem statement and presents the problem that is taken up in this paper. The proposed model is presented in section 3 . Section 4 provides the validation of the proposed solution.

\section{RELATED WORK}

A group of researchers, at Open University Malaysia, introduce the problem of time and space face by distance learners [12]. It is a proposal of implementing m-learning via short message service (SMS). It is an effort to enhance distance learning flexibility to students to encourage and support ubiquitous learning. The limitations of the proposal are high cost, limited number of characters in a single message, use of text message only and late delivery of SMS. There is no evidence in support of the proposal in real time communications between student and instructors.

Lee and Salman [13] discuss the technical, physical and security limitations of using mobile and wireless network in learning process. These limitations influence the performance level, privacy, confidentiality problem 
and high operational costs. It is a proposal of designing and developing standalone client/server application using android platform. The limitations of the proposal are installing, updating and maintaining the application on device those will consume high device storage and more cost. Other problems in the proposal are that it supports only android devices platform and it has low network transmission rate and limited data processing (computing) power.

Several researches have investigated potentials of the educational paradigm shift from the traditional teaching approaches to adaptive and personalized learning [14]. This has led to an increased interest on context-aware adaptive and personalized mobile learning systems with the emerging mobile devices technology to facilitate teaching and learning strategies. The aim is to provide learning experiences delivering via mobile devices and tailored to learner's personal characteristics and situations. It is a proposal of presenting context-aware adaptive and personalized mobile learning system, namely the Units of Learning mobile Player (UoLmP) aiming to support semi-automatic adaptation of learning activities. The main limitations are resources consuming, low battery life, android platform dependency, low network transmission rate and limited data processing (computing) power to analysis data. There is no real time communications between students [14].

Masud et al. [1] discuss m-learning high cost and lack of sufficient educational resources. It is a proposal of mleaning cloud computing architecture. It is an effort to enhance m-learning architecture by cloud computing and using mobile phone technology as a supplement to the existing learning technologies. The objective is to investigate the technical capabilities of different wireless technologies, and determining their suitability to an mlearning environment. The limitations of the proposal are limited processing power, input capability, lack of resources and memory capacity, small screen and no validation.

A study discusses the hardware/software limitations using mobile in learning process [5]. It is a proposal of presenting cloud computing based m-learning system model, the functional design and architecture framework for the system. The limitations of the proposal are limited data processing (computing) power, and no validation of the proposed cloud computing based m-learning model.

Saranya and Vijayalakshmi [15] discuss m-learning high cost and lack of sufficient (hardware/software) resources. It is a proposal of developing interactive mobile live video learning system in cloud environment. The limitations of the proposal are installing the application in the devices which will consume the storage, limited data processing (computing) power, and it is not attach to educational organization or institution.

A study [16] presents Mobi4Ed mobile educational tool to take advantage of cloud computing. The tool processes complex and large computations and images and videos. Students can assess several algorithms in real-time using this tool. It is an effort to help students to understand and compare different algorithms using mobile devices such as de-blurring, de-noising, face detection etc. The limitations of the proposal are android platform dependency, no evidence to include real time video and no assessment to quantify and validate the usefulness of the tool.

Paduri and Conradie [17] discuss how to improve the current initiation system of education and its quality and affordability. It is a proposal of presenting a conceptual framework for educational cloud architecture design. The limitations of the proposal are not covering the relevant aspects related to design and development of a mobile cloud computing architecture. It provides a generic view of the mobile cloud computing architecture.

A group of researchers introduce limitations of devices used for m-learning (usable memory capacity, screen size, problems with slow connections and reduced interface response speed, etc.), and the difficulties to apply existing electronic learning (e-learning) to ubiquitous $\mathrm{m}$ learning without modification [18]. It is a proposal of presenting a model for mobile cloud learning system and its application. It is an effort to enhance the m-learning system. The limitations of the proposal are the paper doesn't mention any details to describe the model, limited data processing (computing) power, and no validation of the proposed mobile cloud learning model.

Masud and Huang discuss how to deploy m-learning with the increased number of users, services, education contents and resources [19]. It is a proposal of presenting new architecture for mobile distance learning system in an extended cloud computing environment enriched with mobiles and wireless devices. It is an effort to overcome the m-learning obstacles related to the performance (battery life, storage, and bandwidth), environment (heterogeneity, scalability and availability), and security (reliability and privacy). The limitations of the proposal are limited data processing (computing) power, and the paper doesn't validate the work. The paper will work further on improving the bandwidth, and implementing more effective dynamic network monitoring.

The study [20] examined high school students' visual clue to the function of an object for social media. The objective is to know the approaches and ideas about emerging technologies, and allied problems and matters. The results reflect that students highly depend on social media in their daily lives for entertainment and community connections. The results recommend that social media is a helpful learning tool. There is neither clear indication of the research question nor methodological aspects to understand the empirical evaluation of research. The research design described for evaluation is survey and it is not the most appropriate research method to evaluate the impact of research.

The research problem is formulated as follows $[5,15$, 18, 19].

How to improve quality and affordability of m-learning system with the increased number of users, services, education contents and resources?

\section{THE PROPOSED SOLUTION}


This paper proposes a cloud computing model for Mlearning system using HPC and GPU cluster infrastructure as shown in fig. 1. The proposed model increases the speed of search, development and it helps to perform high performance computations like science and engineering applications. The science or engineering applications require high bandwidth, low latency networking, and computational resources to conclude decisions.

The proposed model incorporates communication between end-user devices, system server platform, management layer (logical layer), and base layer (infrastructure layer) using cloud computing environment. The users of the system are learners (students), instructors, parents and managers (including system administrators). A user's device connects to the system through external network/Internet or through the local area network (LAN) in order to perform tasks like learn, communicate, download learning materials, access resources, enroll new students, view the student progress and configure the system. The system server platform, in cloud environment, connects the user's device with logical layer. The user accesses the system server platform to perform data processing using HPC, data downloading using cloud services and data rendering using GPU. A user needs data to process by HPC cluster infrastructure. The user's request is sent to the logical layer to map with the needed HPC functions to display the output. The logical layer acts as the brain of the system to complete a request with high performance and smooth flow. The infrastructure contains the basic environment of the system like databases, networks, storages, IT resources, computing, HPC cluster (that builds a massive parallel computer from a set of small machines) and GPU cluster (that is computer cluster in

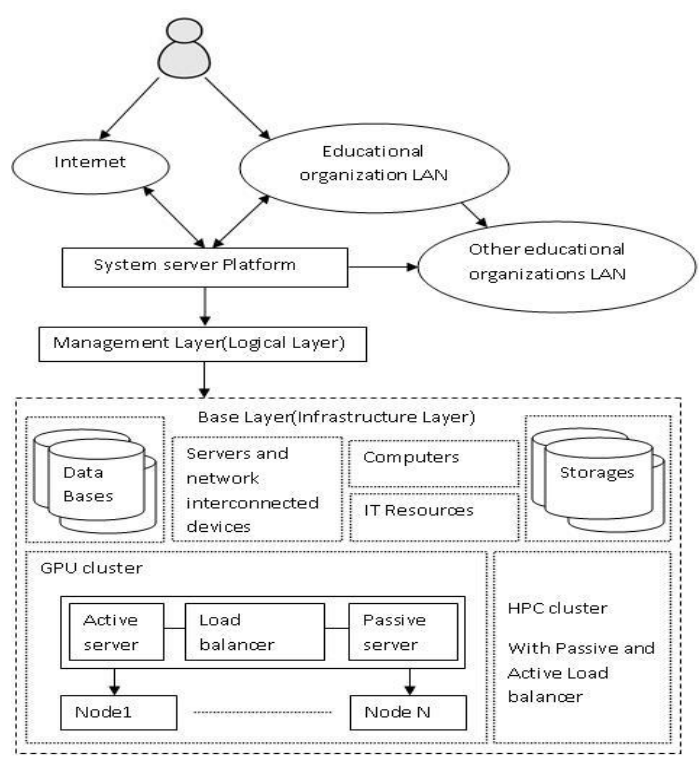

Fig. 1. The Proposed cloud computing model for M-learning

which each node is equipped with a GPU). It is possible to perform very fast calculations with a GPU cluster by harnessing the computational power of modern GPUs via General-Purpose Computing on Graphics Processing
Units (GPGPU). The load balancer is used in GPU cluster to increase performance by distributing the load among different nodes in the cluster. It is installed in front of all nodes. In case of a node failure the remaining node(s) will take over the responsibility to service future requests. The model consists of four layers: the user and device layer, the applications layer, the logical layer and the infrastructure layer.

\section{A. The User and Device Layer}

This layer is used to communicate with the devices using browsers to access the system server platform either by Internet or LAN to authenticate users. Students, instructors, parents and managers need to register as in the traditional systems. The users can change their information, password and other account setting after authentication, through the Account Setting component in the applications layer. This layer also provides transparency at the device and network levels so that users are unaware of their devices applicability or the underlying protocols. The data is different for each user depending on the role of user (student, manager/staff/system administrator, instructor, and parent). It can be divided into dynamic parameters (like protocol, location and time) and static parameters (like name, age, gender, address, E-mail, mobile telephone numbers, native language, free time, user's interests, device information, user level, social media accounts). The dynamic parameters are updated automatically by the system but the static parameters are entered by the users. This process is followed by all users. Furthermore, the user is allowed to reset the password in case it is forgotten. This is accomplished by sending the new password after user's request as an SMS or E-mail. The user's data is encrypted to provide security.

\section{B. Applications Layer (services)}

Application layer provides various services to each user. This layer consists of many components that are integrated to each other. Application layer is scalable by plugging new components. Following are the main components of application layer.

- Users Account component is integrated with the existing user's account. It allows the users to update their static personal information like change the password, change other information and social media accounts.

- Calendar component provides a reminder service where the users can flag activities. It is automatically updated by the system to include dates for assignments, exams, reports and meeting. The user can update information on it manually to include meetings and other activities such as medical appointments. It provides the user weekly schedule that can be displayed on day to day basis. When the user access the system it will be automatically connect to the device calendar in order to update and save the reminder notes like assignments, exams, reports, course lecture and 
meetings on the device. In case if the user is offline then he/she can be reminded about activities. Parents can use this component to schedule meetings with the instructors. Managers can use calendar component to schedule maintenance of system. Managers can set meetings with staff.

- Student Progress component- It provides information about student progress, including grades, attendance, and instructors' comments, student reports. The instructors feed information can be checked by students and parents. Parent can communicate with the instructor using the interactive classroom tool via meeting choice in order to discuss how to improve the student learning progress.

- Previous Session component- Users can keep track of the last session especially when communication is aborted accidently. The last session information is stored in the system. It allows the users to reopen a particular session.

- Learning Courses and Labs component- It consists of a set of services for students and instructors about course objective, learning target, learning plan, instructor name, the related references, online materials, exams and, results. Student can delay the result if he/she does not want to see it immediately. Student can set a reminder for a specific period. User can access the system to know his/her mistakes in exams, lecture notes, the recorded video of the lecture, assignments, social media, email, practice exercises, labs handouts, instructors' announcements, simulation environment, interactive tool to communicate course or lab discussion and board to post questions, comments, and answers.

- Learning resources component- It provides a database of digital educational resources that can be accessed by students and instructors such as course materials, lecture slide and video/audio. Library service is used to check availability of resources in library, digital libraries, online materials and other learning database resources.

- Interactive Classroom Tool component- It provides real time communication between students and instructors. It can be used by parents to communicate with the instructor to discuss student progress and it can be used by managers to communicate with staff. Cisco WebEx, Udacity for iPad are the main tools. Students use their mobile devices (mobile smart phones, or tablets) to connect to the course via their mobile networks (such as GPRS, UMTS, HSPA, Wi-Fi, WiMAX or LTE).

- System Management component- This component is designed to serve managers and it is integrated with all components of the system.

\section{Logical layer}

This layer maps the services to their clusters services by managing the underlying resource. It is responsible for maps between the user requests and the needed hardware or software to accomplish it. The logical layer schedules user's requests and it provisions the needed resources to access the services of cloud or system efficiently and securely.

\section{Infrastructure Layer}

This layer provides the basic environment including computers, storage; servers, networking, database resources, IT resources, data, network, storage resource pool, GPU cluster and HPC cluster.

\section{VALIDATION}

In order to validate the proposed model, Survey was conducted. The purpose of adopting this method it is not consuming time and the answer will be using likert scale which is a thoughtful way. A closed ended questionnaire consisting of 29 questions was distributed among different users (student/instructor/manager, staff, and system administrator from different educational organization/parent). Five goals were used for data gathering. Questions were arranged according to their relevancy to defined goals.

Goal 1. Frequency of using mobile devices and its applications and users beliefs.

Goal 2. Anywhere and anytime (mobility).

Goal 3. Better services for better learning and build a relationship with the system (productivity).

Goal 4. Interactive communication with privacy.

Goal 5. Fast respond with high performance (data processing time).

The response was gathered from $43 \%$ students, $18 \%$ instructors, $28 \%$ parents and $12 \%$ managers. The data was gathered and analyzed through Google tools and excel for statistical analysis. The results are concluded mainly through frequency tables showing the exact degree of analysis.

\section{A. Cumulative Statistical Analysis of Goal 1}

The results are shown in Table 2.

Table 2. Cumulative Statistical Analysis of goal 1

\begin{tabular}{|c|c|c|c|c|c|}
\hline Q. no. & Very low & Low & Nominal & High & Very high \\
\hline 1 & 2 & 4 & 6 & 8 & 46 \\
\hline 2 & 1 & 3 & 8 & 12 & 42 \\
\hline 4 & 1 & 1 & 5 & 27 & 32 \\
\hline \hline 5 & 4 & 11 & 6 & 16 & 29 \\
\hline \hline Total & 8 & 19 & 25 & 63 & 149 \\
\hline \hline Average & 2 & 4.75 & 6.25 & 15.75 & 37.25 \\
\hline Percentage & $3 \%$ & $7 \%$ & $9 \%$ & $24 \%$ & $57 \%$ \\
\hline
\end{tabular}

It is shown in Table 2 that $57 \%$ and $24 \%$ of the respondents supported very high and high to the goal $1.7 \%$ of the sample supported to low and $3 \%$ of the sample agreed to very low. $9 \%$ of the sample chose to be neutral.

\section{B. Cumulative Statistical Analysis of Goal 2}



3.

Cumulative static analysis of goal 2 is shown in Table

Table 3. Cumulative Statistical Analysis of goal 2

\begin{tabular}{|c|c|c|c|c|c|}
\hline Q. no. & Very low & Low & Nominal & High & Very high \\
\hline \hline 2 & 1 & 3 & 8 & 12 & 42 \\
\hline \hline 3 & 1 & 2 & 8 & 20 & 35 \\
\hline \hline 8 & 2 & 3 & 5 & 15 & 28 \\
\hline \hline 9 & 5 & 2 & 5 & 10 & 30 \\
\hline \hline 10 & 1 & 3 & 5 & 9 & 27 \\
\hline \hline 12 & 1 & 1 & 7 & 13 & 31 \\
\hline \hline 13 & 1 & 2 & 4 & 15 & 44 \\
\hline \hline 14 & 3 & 1 & 6 & 10 & 34 \\
\hline \hline 18 & 1 & 4 & 6 & 14 & 28 \\
\hline \hline 19 & 1 & 1 & 8 & 17 & 26 \\
\hline \hline Total & 17 & 22 & 62 & 135 & 325 \\
\hline \hline Average & 1.7 & 2.2 & 6.2 & 13.5 & 32.5 \\
\hline \hline Percentage & $3 \%$ & $4 \%$ & $11 \%$ & $24 \%$ & $58 \%$ \\
\hline
\end{tabular}

It is cleared from the Table 3 that $58 \%$ and $24 \%$ of the sample believed that the mobile devices usage and cloud computing will enhance the learning process. $4 \%$ and $3 \%$ of the respondents were not agreed. $11 \%$ of the sample remained neutral.

\section{Cumulative Statistical Analysis of Goal 3}

Cumulative analysis of goal 3 is shown in Table 4.

Table 4. Cumulative Statistical Analysis of goal 3

\begin{tabular}{|c|c|c|c|c|c|}
\hline Q. no. & Very low & Low & Nominal & High & Very high \\
\hline 6 & 2 & 2 & 1 & 19 & 42 \\
\hline 7 & 1 & 1 & 8 & 14 & 42 \\
\hline 8 & 2 & 3 & 5 & 15 & 28 \\
\hline 9 & 5 & 2 & 5 & 10 & 30 \\
\hline 10 & 1 & 3 & 5 & 9 & 27 \\
\hline 11 & 2 & 2 & 7 & 7 & 14 \\
\hline 12 & 1 & 1 & 7 & 13 & 31 \\
\hline 13 & 1 & 2 & 4 & 15 & 44 \\
\hline 14 & 3 & 1 & 6 & 10 & 34 \\
\hline 16 & 1 & 3 & 3 & 10 & 28 \\
\hline 18 & 1 & 4 & 6 & 14 & 28 \\
\hline 19 & 1 & 1 & 8 & 17 & 26 \\
\hline 20 & 2 & 2 & 3 & 17 & 29 \\
\hline 24 & 6 & 1 & 11 & 22 & 26 \\
\hline 25 & 1 & 6 & 14 & 14 & 31 \\
\hline 26 & 1 & 3 & 10 & 15 & 37 \\
\hline 28 & 1 & 1 & 5 & 13 & 46 \\
\hline 29 & 1 & 3 & 1 & 5 & 56 \\
\hline Total & 33 & 41 & 109 & 239 & 599 \\
\hline Average & 1.8 & 2.3 & 6.1 & 13.3 & 33.3 \\
\hline Percentage & $3 \%$ & $4 \%$ & $11 \%$ & $24 \%$ & $58 \%$ \\
\hline
\end{tabular}

According to Table 4, 58\% of the respondents are very highly agreed with goal 3 and $24 \%$ of the sample believed in the goal $3.4 \%$ and $3 \%$ of the sample were not agreed with the goal $3.11 \%$ of the sample remained neutral.

\section{Cumulative Statistical Analysis of Goal 4}

The cumulative analysis of goal 4 is shown in Table 5.

Table 5. Cumulative Statistical Analysis of goal 4

\begin{tabular}{|c|c|c|c|c|c|}
\hline Q. no. & Very low & Low & Nominal & High & Very high \\
\hline \hline 13 & 1 & 2 & 4 & 15 & 44 \\
\hline \hline 14 & 3 & 1 & 6 & 10 & 34 \\
\hline \hline 15 & 4 & 5 & 9 & 8 & 40 \\
\hline \hline 18 & 1 & 4 & 6 & 14 & 28 \\
\hline \hline 19 & 1 & 1 & 8 & 17 & 26 \\
\hline \hline 21 & 1 & 2 & 5 & 12 & 27 \\
\hline \hline 22 & 2 & 1 & 5 & 23 & 23 \\
\hline \hline 23 & 1 & 4 & 8 & 20 & 33 \\
\hline \hline Total & 14 & 20 & 51 & 119 & 255 \\
\hline \hline Average & 1.75 & 2.5 & 6.38 & 14.88 & 31.88 \\
\hline \hline Percentage & $3 \%$ & $4 \%$ & $11 \%$ & $26 \%$ & $56 \%$ \\
\hline
\end{tabular}

Table 5 shows that $56 \%$ of the respondents are very highly in favor of goal 4 while $26 \%$ of the respondents are highly supported the goal 4 . Overall $7 \%$ of the respondents are against the goal $4.11 \%$ of the respondents are remained neutral.

\section{E. Cumulative Statistical Analysis of Goal 5}

Questions under this goal show that how much users are interested in continues services with high performance, fast respond and security of the proposed model. The results are shown in Table 6 .

Table 6. Cumulative Statistical Analysis of goal 5

\begin{tabular}{|c|c|c|c|c|c|}
\hline Q. no. & Very low & Low & Nominal & High & Very high \\
\hline \hline 3 & 1 & 2 & 8 & 20 & 35 \\
\hline \hline 17 & 2 & 0 & 9 & 10 & 32 \\
\hline 18 & 1 & 4 & 6 & 14 & 28 \\
\hline 19 & 1 & 1 & 8 & 17 & 26 \\
\hline \hline 26 & 1 & 3 & 1 & 15 & 37 \\
\hline \hline 27 & 1 & 2 & 5 & 15 & 43 \\
\hline \hline Total & 1 & 3 & 1 & 5 & 56 \\
\hline \hline Average & 1.14 & 2.14 & 6.71 & 13.71 & 36.71 \\
\hline \hline Percentage & $2 \%$ & $4 \%$ & $11 \%$ & $23 \%$ & $60 \%$ \\
\hline
\end{tabular}

Table 6 shows that $60 \%$ of the respondents do have a very high support for the goal $5.23 \%$ of the respondents are highly interested in continues services with high performance, fast respond and security of the proposed model. $6 \%$ of the respondents are against this feature and $11 \%$ of the respondents are remained neutral.

\section{F. The Final Cumulative Evaluation of all goals}

The results, of final cumulative statistical analysis of the 5 goals, are shown in Table 7. It is shown in Table 7 
that $82 \%$ (24\% and $58 \%)$ of respondents support the proposed model. $11 \%$ of the respondents remained neutral. $5 \%$ and $3 \%$ of the respondents support low and very low to the proposed model.

Table 7. Cumulative Statistical Analysis of 5 goals

\begin{tabular}{|c|c|c|c|c|c|}
\hline All Q. & Very low & Low & Nominal & High & Very high \\
\hline \hline Percentage & $3 \%$ & $5 \%$ & $11 \%$ & $24 \%$ & $58 \%$ \\
\hline
\end{tabular}

\section{CONCLOUSION}

Mobile devices are widespread and provide great capabilities to deliver M-learning. There are numerous educational organizations who cannot afford expensive resources to implement $\mathrm{M}$-learning. Cloud computing is the best solution for such institutions who want to implement M-learning system with its dynamic scalability and low cost. This paper presents new model of M-learning system in cloud computing environment extended by the power of HPC and GPU cluster infrastructure. A validation of the proposed model was performed. It was concluded that $82 \%$ of respondents support the proposed model.

\section{REFRENCES}

[1] Masud, Anwar Hossain; Jianming Yong; Xiaodi Huang;, "Enhanced M-Learning with cloud computing: The Bangladesh case," Computer Supported Cooperative Work in Design (CSCWD), 15th International Conference on IEEE, vol., no., pp.735-741, 8-10 June. 2011.

[2] http://en.wikipedia.org/wiki/Distance_education\#Distance _e-Learning. Accessed 2014.

[3] Shuai, Qin; Zhou Ming-Quan.;, "Cloud computing promotes the progress of m-learning," Uncertainty Reasoning and Knowledge Engineering (URKE), International Conference on IEEE, vol.2, no., pp.162-164, 4-7 Aug. 2011.

[4] Verma, Kritika; Dubey, Sonal; Dr.M.A.Rizvi;",Mobile Cloud A New Vehicle for Learning: m-Learning Its Issues and Challenges," International Journal of Science and Applied Information Technology,vol.1, no.3, pp. 93-97, July - Aug. 2012.

[5] Chen, Shaoyong; Min Lin; Huanming Zhang; "Research of mobile learning system based on cloud computing,"eEducation, Entertainment and e-Management (ICEEE), International Conference on IEEE, vol., no., pp.121-123, 27-29 Dec. 2011

[6] http://en.wikipedia.org/wiki/M-learning\#Challenges. Accessed 2014.

[7] Hirsch, Benjamin; Jason WP Ng., "Education beyond the Cloud: Anytime-anywhere learning in a smart campus environment," Internet Technology and Secured Transactions (ICITST), International Conference on IEEE, vol., no., pp.718-723, 11-14 Dec. 2011.

[8] M. Tantow: Cloud Computing and Smartphones. Cloud Times.http://cloudtimes.org/2011/03/01/cloud-computingand-smartphones/ (01 March 2011).Accessed 2014.

[9] http://insidehpc.com/hpc-basic-training/what-is-hpc/. Accessed 2014.

[10] Douglas Eadline: Moving HPC to the Cloud. admin magazine.http://www.admin-magazine.com/HPC/Articles/ Moving-HPC-to-the-Cloud. Accessed 2014.
[11] http://en.wikipedia.org/wiki/Graphics_processing_unit. Accessed 2014.

[12] Lim, Tina; MansorFadzil; NorziatiMansor;,"Mobile Learning via SMS at Open University Malaysia: Equitable, Effective, and Sustainable," International Review of Research in Open \& Distance Learning, vol.12, no.2, pp.122-137, Feb. 2011.

[13] Kwang B. Lee; Raied Salman;,"The Design and Development of Mobile Collaborative Learning Application Using Android, " Journal of Information Technology and Application in Education, vol.1, no.1, pp.1-8, 2012.

[14] Gómez, Sergio, et al.;"Context-Aware Adaptive and Personalized Mobile Learning Delivery Supported by UoLmP," Journal of King Saud University-Computer and Information Sciences, vol.26, no.1, pp.47-61, 21 Oct. 2013.

[15] Saranya, S. Mohana; M. Vijayalakshmi;, "Interactive mobile live video learning system in cloud environment," Recent Trends in Information Technology (ICRTIT), International Conference on IEEE, vol., no., pp.673-677, 3-5 Jun. 2011.

[16] Ferzli, Rony; Ibrahim Khalife;, "Mobile cloud computing educational tool for image/video processing algorithms," Digital Signal Processing Workshop and IEEE Signal Processing Education Workshop (DSP/SPE), IEEE, vol., no., pp.529- 533,4-7 Jan. 2011.

[17] Veerabhadram, Paduri; Pieter Conradie;,"Mobile cloud framework architecture for education institutions, " Science and Information Conference (SAI), IEEE, vol., no., pp.924-927, 7-9 Oct. 2013.

[18] Lee, Jae Dong; Jong-Hyuk Park; , "Application for Mobile Cloud Learning," Network-Based Information Systems (NBIS), 16th International Conference on IEEE, vol., no., pp.296- 299, 4-6 Sept. 2013.

[19] Masud, A. Hossain; Xiaodi Huang; "A Cloud Based Mlearning Architecture for Higher Education," Archives Des Sciences, vol.66, no.1, pp.751-760, Jan. 2013.

[20] Mao, Jin; "Social media for learning: A mixed methods study on high school students' technology affordances and perspectives," Computers in Human Behavior on Science Direct, vol.33, no., pp.213-223, April 2014.

\section{Authors' Profiles}

Areej Omar Baalghusun Post-graduate student for master degree for Information Technology in King Abdul-Aziz University. She received a Bachelor in Computer Science in 2009 and worked in 3D animation projects during undergraduate program.

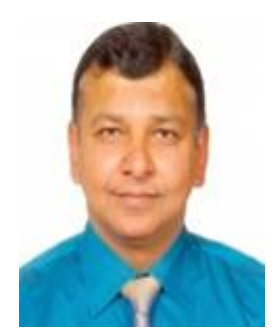

Dr. M. Rizwan Jameel Qureshi received his Ph.D. Computer Sciences degree from National College of Business Administration \& Economics, Pakistan 2009. He is currently working as an associate Professor in the department of Information Technology, Faculty of Computing \& Information Technology, King Abdul-Aziz University. He is the best researcher awardees of King Abdul-Aziz University Saudi Arabia in 2013 and Department of Computer Science, COMSATS Institute of Information Technology Pakistan in 2008. 